\title{
Current advances in multiple sclerosis immunopathology
}

Carlos Fredy Cuevas-García, Nora Hilda Segura-Méndez and Diana Andrea Herrera-Sánchez

Instituto Mexicano del Seguro Social, Centro Médico Nacional Siglo XXI, Specialty Hospital "Dr. Bernardo Sepúlveda Gutiérrez", Ciudad de México, Mexico

\begin{abstract}
Multiple sclerosis is a demyelinating inflammatory disease that affects the central nervous system. Its etiology is the result of a complex interaction between genetic and environmental factors that trigger a deregulated immune response, with the resulting inflammation and neuronal/axonal degeneration. Neuroinflammation is triggered when peripheral leukocytes migrate to the central nervous system and release cytokines such as interleukins 1 and 6 (IL-1 and 6) and tumor necrosis factor (TNF), which act on dwelling cells. The innate immune system plays an important role in the onset and progression of the disease by identifying molecular patterns associated with pathogens and damage, which modulate effector and regulatory functions of the cells where they are expressed, in order to direct the specific immune response. Th17 cells favor the disruption of the blood-brain barrier, which enables the migration of leukocytes to the central nervous system and the triggering of the inflammatory cascade; the Th1 profile (IL-1, IL-6) collaborates to perpetuate it. B-cell function is to produce antibodies and cytokines (IL-6, IL-12 and TFN). Knowledge on multiple sclerosis pathophysiology will enable the development of new therapeutic options that impact on natural history of the disease and its prognosis.
\end{abstract}

KEY WORDS: Multiple sclerosis. Cytokines. Innate immunity. Humoral immunity.

\section{Introduction}

Multiple sclerosis (MS) is a chronic autoimmune inflammatory disorder predominantly mediated by T cells, which induce multifocal demyelination and gliosis with loss of oligodendrocytes and axons. It is the result of a complex interaction between genetic susceptibility and environmental factors such as chronic infection with the Epistein-Barr virus (EBV), smoking and vitamin D deficiency.

Its pathophysiology is determined by damage to the myelin sheath that surrounds and protects central nervous system axons induced by autoreactive T cells. Murine models show that experimental autoimmune encephalomyelitis (EAE) can be triggered by the transfer of autoreactive myelin $T$ cells, with consequent neuroinflammation and demyelination.

Over the last two decades, advances in immunology have allowed to know more about humoral and innate immunity, cytokine deregulation and Th17 cells effector profile; strictly speaking, epigenetic changes promote the inflammatory phenotype and demyelination; however, there is still doubt as to how they act on mitochondrial dysfunction, oxidative stress and axonal degeneration.

\section{Multiple sclerosis epigenetics}

Epigenetics studies those DNA changes that influence on gene expression without altering the DNA sequence, and that are produced by environmental factors. DNA methylation, histone modification of and miRNA silencing are the three most important epigenetic mechanisms. ${ }^{1}$

DNA methylation consists of the binding of a methyl group to a cytosine residue in the nucleotide DNA chain, which produces cytosine-guanine dinucleotides $(\mathrm{CpG})$ that cluster in the genome constituting the so-called $\mathrm{CpG}$ islands, a process carried out by DNA methyltransferase enzymes (DNMT). Cytosine residues methylation silences the genes, possibly blocking the binding of transcriptional
Correspondence:

Carlos Fredy Cuevas-García

E-mail: cacu61152@ hotmail.com
Date of reception: $12-04-2017$

Date of acceptance: 08-01-2018

DOI://dx.doi.org/10.24875/GMM.M18000194
Gac Med Mex. 2018;154:498-506

Contents available at PubMed www.gacetamedicademexico.com 
factors; consequently, DNA hypomethylation promotes transcription.

Histone modification is another epigenetic mechanism, which consists of acetylation and deacetylation in lysine residues, carried out by histone acetyltransferases (HAT) and histone deacetylases (HDAC), respectively. Histone acetylation facilitates transcriptional factors binding to DNA, i.e., deacetylation, which inhibits transcription, thus influencing on the inflammatory process.

Epigenetic changes can also be generated at the post-transcriptional level by microRNA (miRNA), non-coding, single-chain RNAs that modulate cell differentiation, proliferation and apoptosis; its deregulation has been associated with autoimmunity and inflammation. ${ }^{2}$

Some risk factors identified in the development of MS are viral infections, especially with EBV, belonging to the female gender, vitamin D deficiency, smoking and a family history of MS.

The most important genetic susceptibility is related to major histocompatibility complex genes, specifically the HLA-DRB1*1501 haplotype, which is most often transmitted by mothers and could be mediated by epigenetic mechanisms such as DNA methylation and histone deacetylation. ${ }^{3}$

EBV generates chronic latent viral infection in the lymphocytes and up-regulates DNMT, influencing on cell proliferation and genome stability; however, only its extractable antigen shows association with the onset of MS. ${ }^{4}$

Vitamin D inhibits IL-17 locus by modifying histone deacetylase 2 (HDAC2) at the IL-17A promoter region; consequently, its deficiency favors Th17 profile. ${ }^{4}$

Smoking has been linked to an increase in relapses and the number of active brain lesions in magnetic resonance imaging (MRI). It alters histone modification, DNA methylation pattern and miRNA expression. In addition, it activates neutrophils, macrophages and monocytes. ${ }^{5}$

\section{Immunopathology}

The presence of the described epigenetic factors is not sufficient to explain MS pathophysiology, where Th1 and Th17 inflammatory phenotypes predominate, with the specific mechanisms that trigger inflammation still remaining to be elucidated.

Most studies on cytokines epigenetic regulation have focused on Th17 profile differentiation, where IL-17 gene promoter regions are shown to undergo histone acetylation and DNA hypermethylation.

Another mechanism by means of which $\mathrm{T}$ cell responses are modulated is miRNA-mediated gene regulation. miR-155 and miR-326 levels of expression are closely related to TCD4 cells differentiation into the Th17 phenotype. ${ }^{5,6}$

Theoretically, the DNA methylation and histone modification processes are susceptible to treatment, targeting enzymes involved in these processes, for example, deacetylase inhibitors; however, they are nonspecific, since epigenetic changes are organ-specific; therefore, MS current treatment continues to be aimed at controlling the inflammatory process. ${ }^{7}$

Next, the function of the most important components of innate and adaptive immunity in MS inflammation will be briefly explained.

\section{Neuroinflammation and the complex cytokine network}

Neuroinflammatory diseases such as MS occur when peripheral leukocytes migrate to the central nervous system (CNS) and release cytokines such as IL-1, IL-6 and TNF, which act on CNS resident cells (e.g., microglia) to produce more cytokines and perpetuate inflammation (Fig. 1).

Cytokines are proteins that regulate cell behavior. Specifically in MS, they favor the Th1 or Th17 effector profile, which causes inflammation, tissue damage and neurological deterioration.

So far, the most important cytokines in MS pathophysiology are the following:

1) IL-23, produced by antigen-presenting cells (APC) in secondary lymphoid tissues and microglia. Its function is to generate and stabilize a specific Th effector phenotype and stimulate the production of IL-17A, IL-17F, IL-22 and granulocyte-macrophage colony stimulating factor (GM-CSF) ${ }^{8,9}$

2) IL-17 acts on stromal and endothelial cells, astrocytes and microglia. It destroys blood-brain barrier (BBB) integrity, which allows leukocyte migration to the CNS and trigger the inflammatory process. Astrocytes respond to IL-17 by producing chemokines that attract neutrophils, which actively collaborate to tissue damage. ${ }^{10}$ Mice lacking the IL-17A gene (IL17a -/- mice) are susceptible to EAE; however, they develop a delayed disease, corroborating the importance of this cytokine in pathophysiology. ${ }^{11,12}$

3) IL-6 is crucial for the development of EAE. It blocks effector Th cells FOXP3 expression, which prevents their regulatory function. It favors IL-1 receptor expression on T cells to stabilize local Th1 profile and counteract the natural tendency towards neuroinflammation resolution. ${ }^{13}$ Uninterrupted expression of these cytokines and continuous arrival of leukocytes to the CNS perpetuate inflammation. 


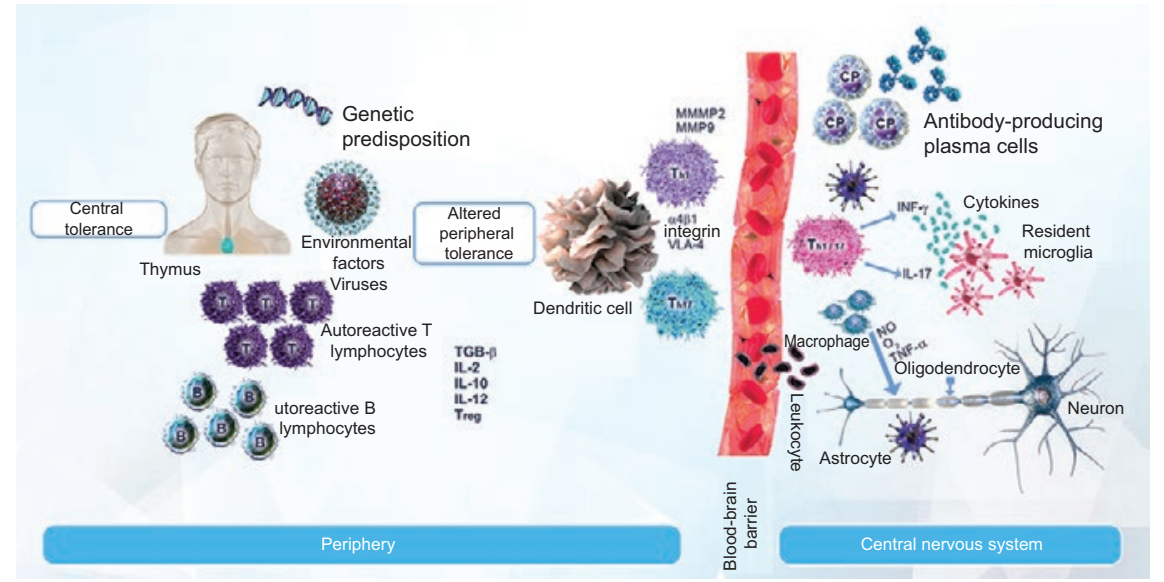

Figure 1. Multiple sclerosis pathophysiology. Naïve Tlymphocytes that escape peripheral tolerance are recruited and activated by autoantigens, to be shown to antigen-presenting cells. In the presence of a favorable microenvironment (genetic, hormonal, factors, infections, immunodeficiencies), proliferation of autoreactive lymphocytes that produce antibodies or activate antigen-specific cytotoxic T cells will increase. If peripheral tolerance mechanisms are not able to control autoreactive T lymphocytes through suppressor cells such as $T_{\text {reg, }}$ an autoimmune disease will clinically appear. In the context of MS, dendritic cells initiate and direct the innate and adaptive immune responses that promote the development of cytokine-producing Th17 and Th1 effector cells that will act on resident cells of the CNS, which will trigger neuroinflammation. $T_{\text {reg }}=$ regulatory $T$ cell, IL = interleukin, TGF- $\beta=$ transforming growth factor beta, STAT = signal transducer and activator of transcription, TNF- $\alpha=$ tumornecrosis factor alpha, IFN = interferon, VLA-4 = very late antigen-4, MMP2 = matrix metalloproteinase-2; MMP9 = matrix metalloproteinase-9.

4) Interferon gamma (IFN- $\gamma$ ) was central in MS pathophysiology until a couple of decades ago; currently, it is difficult to define its role since it acts on many cell types and has pro- and anti-inflammatory properties that appear to depend on the microenvironment, the dose and the specific moment of exposure (Table 1). In MS, it exerts a predominantly inhibitory effect in the CNS and excitatory in the spinal cord. ${ }^{14}$ IFN- $\gamma$ injection directly into the CNS triggered inflammation in murine models, ${ }^{15}$ but administration of blocking antibodies and the lack of genes to code it exacerbated EAE, ${ }^{16}$ also suggesting a protecting role on neuroinflammation.

5) Tumor necrosis factor (TNF) is produced by macrophages and TCD4 and TCD8 cells, among others, and has pro- and anti-inflammatory functions (Table 1). Its blockade in patients with MS led to more frequent and serious relapses. ${ }^{17}$ The cause was probably the diversity of receptors it can bind to.

6) GM-CSF is a cytokine produced by $T$ cells in response to IL-23 and has been associated with neurodegenerative functions of microglia. It represents the means of communication between T-lymphocytes and myeloid cells recruited in response to GM-CSF, with the latter being relevant to the CNS because they phagocytose and induce receptor-mediated apoptosis and are the main source of reactive oxygen species. ${ }^{18}$

7) Transforming growth factor beta (TGF- $\beta$ ) is a cytokine that has three isoforms and the expression of each one is spatially and temporally different. TGF- $\beta 1$ is present in the immune system and both TGF- $\beta 2$ and TGF- $\beta 3$ are expressed in neurons and glia; infiltration of the CNS by Th1 cells in patients with MS is partially regulated by TGF- $\beta$ functions (Table 2 ). ${ }^{19}$

The interest in TGF- $\beta$ within the pathophysiology of MS has increased after the observation that IL-6 + TGF- $\beta$ drives murine Th17 cell differentiation in vitro, even in the absence of transcription factor T-bet, which regulates Th1 and Th17 profile.19,20

Under normal conditions, the presence of TGF- $\square$ in lymph nodes, where naïve T lymphocytes typically find the antigen, suppresses $T$ cell activation and differentiation, even in the presence of Th1-promoting cytokines, such as IL-12.

In areas of CNS inflammation of patients with MS, the production of Th1 cytokines can increase, while IL-10 expression is favored, which counteracts Th1 effector cells activity against myelin. ${ }^{21}$

The absence of TGF- $\beta 1$ signaling results in spontaneous $T$ cell differentiation and autoimmunity. ${ }^{22,23}$ TGF- $\beta$ induces the Th9 profile, which is associated with Th17 cells negative regulation. ${ }^{24}$

8) IL-9 in the cerebrospinal fluid (CSF) of patients with MS is negatively correlated with inflammation, neurodegeneration and disease progression, which supports its regulatory role. ${ }^{25}$ In vitro, the proliferation of oligodendrocyte precursor cells is promoted by the Th9 profile together with IFN- $\gamma$, but is inhibited in the presence of IL-17.26 
Table 1. IFN- $\gamma$ and TNF functions in multiple sclerosis

Produced by lymphocytes.

Inhibits IL-17

Favors BBB integrity, through the expression of binding proteins in endothelial cells.

Promotes myelin degradation products phagocytosis by APCs.

Prevents neurotoxic products accumulation (by promoting phagocytosis).
Produced by myeloid cells, lymphocytes.

Induces oligodendrocyte apoptosis.

Lowers glutamate absorption by astrocytes.

Stimulates adhesion molecules expression in endothelial cells and astrocytes ( $T$ cell extravasation through the BBB and brain parenchyma).

Synergistically with IFN- $\gamma$ it promotes the expression of $\mathrm{MHC}$ molecules on astrocytes and oligodendrocytes, which magnifies TCD8+cytotoxicity.

$\overline{\mathrm{APC}}=$ antigen-presenting cell, $\mathrm{BBB}=$ blood-brain barrier, IFN- $\gamma=$ interferon gamma, $\mathrm{MHC}=$ major histocompatibility complex, $\mathrm{TNF}=$ tumor necrosis factor.

\section{Innate immunity}

The innate immune system plays an important role in the onset and progression of the disease, through the modulation of $T$ and $B$ cell effector functions; we will focus exclusively on the pattern recognition Toll-like receptors (TLR), autophagy, inflammasomes and natural killer (NK) cells.

\section{TLR}

TLRs are transmembrane glycoproteins that are expressed in myeloid cells, CPA, T and B lymphocytes. They can bind to a broad range of microbial ligands and endogenous damage-associated molecular patterns (DAMP) or alarmins such as HSP70 (Heat Shock Proteins 70 ) and HMGB1 (high-mobility group protein 1), produced as a result of tissue damage or cell death.

In addition to identification of pathogen-associated molecular (PAM) and DAM patterns, their function is to modulate effector and regulatory functions of cells where they are expressed, i.e. they represent a point of union between innate and adaptive immunity.

In MS, the most widely studied is TLR2, identified in endothelial cells, microglia, astrocytes and oligodendrocytes; it occurs as a homodimer or heterodimer associated with TLR1 or TLR6. ${ }^{27}$ TLR2 stimulates the production of IL-1, IL-6, IL-12 and IL-23, favoring the Th1 and Th17 profiles; jointly, it influences on $T$ regulatory $\left(T_{\text {reg }}\right)$ cells function. ${ }^{28}$

In the CNS, it can contribute to neuroinflammation via a PARP-1-dependent pathway. ${ }^{29}$

TLR2 is stimulated by infectious agents (pathogens or commensals) that, in case of not being limited, will cause a decrease in $T_{\text {reg }}$ cells and escape of preexisting autoreactive T cells. The production of IL-1 and IL-6 as a result of stimulation will inhibit inducible $\mathrm{T}_{\text {reg }}\left(\mathrm{iT} \mathrm{T}_{\text {reg }}\right.$ ) cells
Table 2. TGF- $\beta$ functions

Inhibits the production of IL-2, IL-12 (Th1).

Decreases the production of IFN- $\gamma$, as a consequence of Th1 blockade.

Promotes $T_{\text {req }}$ differentiation.

Activates TCD8+cells.

Favors the Th9 profile.

TGF- $\beta=$ transforming growth factor beta.

differentiation, which are important for peripheral tolerance, contributing to the $T_{\text {reg }}$ cell defect that is known in patients with MS. ${ }^{30,31}$

TLRs play an important role in the regulation of autoimmunity attributable to PRR (pattern recognition receptors) and DAM identification, with the latter being capable of triggering an inflammatory response in the absence of an infectious stimulus.

\section{Autophagy}

It is a lysosome-dependent degradation pathway that eliminates unnecessary organelles and proteins for energy recycling. There are three subtypes of autophagy: macrophagy, chaperone-mediated autophagy and mitophagy, with the latter being responsible for dysfunctional mitochondria degradation.

Autophagy maintains mitochondrial homeostasis by decreasing reactive oxygen species, which are important in neuroinflammation. ${ }^{32}$ Autophagy blockage or dysfunction causes inflammasome activation and neurodegeneration.

\section{Inflammasomes}

These are proteins that form signaling complexes that are sensitive to damage and stress, influence on the production of IL-1 $\beta$ and IL-18 cytokines by means of caspase- 1 activation and piroptosis. They do not possess a signaling sequence for their secretion and are produced from an inactive form, pro-IL-1 $\beta$ and pro-IL-18. The NLRP3 
inflammasome -the most widely studied- promotes leukocyte migration to the CNS in EAE. ${ }^{33}$ Caspase- 1 and IL-1 $\beta$ have been identified in plaques of patients with $\mathrm{MS},{ }^{34}$ and the levels of IL-1 $1 \beta$ in the CSF have been proposed to be able to be used as predictors of in situ response to treatment, disease severity and progression. ${ }^{35}$ Pharmacologically, IFN- $\beta$ decreases NLRP3 expression ${ }^{36}$ and IL-1 $\beta$ plasma levels in patients with MS. ${ }^{37}$

However, even when there are first-line treatments for MS, their use is not successful in all patients. There is a dependence of their effects on NLRP3 and this feature divides the patients in IFN- $\beta$ responders and non-responders. ${ }^{38}$

The former show NLRP3 and IL- $\beta$ decreased levels before treatment, while non-responders show upregulation 3 months after treatment with IFN- $\beta{ }^{38,39}$ NLRP3-independent EAE is resistant to IFN- $\beta$ and shows minimal remission due to irreversible neuronal damage.

\section{Natural killer cells}

NK cells are part of innate immunity and comprise a subpopulation of lymphocytes that phenotypically express CD16 or CD56 on their surface, in the absence of CD3. NK subpopulations are the following: CD56 bright, CD56 $^{\text {dim }}$ CD16, ${ }^{-}$CD56 ${ }^{\text {dim }} \mathrm{CD}^{+} 6^{+}$and CD56.

NK CD56 $6^{\text {bright }}$ cells, which owe their name to the expression of CD56 on their surface (also known as neural cell adhesion molecule), express the inhibitory receptor NKG2A and represent only $10 \%$ of NK cells.

CPAs modulate NK cells by means of receptors for IL-12, IL-15 and IL-18, which lead to the release of molecules such as IFN- $\gamma$, IL-10 and IL-13, TNF- $\beta$ and GMCSF; their regulatory function is related to the release of these cytokines. ${ }^{40}$

NK cells cytotoxicity can attenuate inflammation in the acute phase by means of $T$ cell and microglia death, but damaging repair during the late stage through neural stem cell death. Interferon release and natural cytotoxicity by NK cells is crucial to innate defense against viruses. Epidemiological studies suggest that herpesviruses are related to the development of MS, specifically EBV. ${ }^{41}$

In contrast with the latter, cytomegalovirus (CVM) has been suggested to protect against the development of MS, but study results are contradictory and probably depend on the host-pathogen complex interaction. CMV infection induces an adaptive reconfiguration of NK cells in healthy adults, through the expansion of the NKG2 ${ }^{\text {bright }}$ subset. In patients with MS and CMV seropositivity, NKG2C expression was associated with lower risk of disease progression, suggesting that it may be beneficial; however, it is uncertain whether NKG2C cells can fully account for the alleged protecting role of CMV in MS. ${ }^{42}$

Some drugs have benefited from NK cells regulating functions.

Antibody-dependent cytotoxicity by NK CD56 dim cells is an essential therapeutic mechanism in $T$ and $B$ cell suppression mediated by alemtuzumab. ${ }^{43}$ Natalizumab increases the number of total NK and peripheral NK CD56 bright cells with a reduced number of NK cells in the $\mathrm{CSF}^{44}$ On the other hand, daclizumab improves immune tolerance endogenous mechanisms by reducing early $T$ cell activation by blocking the IL-2 receptor that allows phenotype CD56 bright expansion. It also favors for NK cells, after binding to T lymphocyte IL-2 receptor, to control direct death, which for CD56 bright involves the release of granzyme. ${ }^{45-47}$

\section{Cell immunity: autoreactivity or regulation?}

\section{Th1 versus Th17}

For decades, the observation that myelin-specific $T$ cells from patients with MS expressed the Th1 profile validated their predominant role in the pathophysiology of the disease..$^{48}$

The finding of IL-17 increased expression in peripheral blood, CSF and CNS lesions in patients with MS, associated with the controversial role of IFN- $\gamma$ and TNF- $\square$ have conferred it a higher relevance. ${ }^{49-51}$

Th1 cells in peripheral blood and CSF are 10-fold higher than Th17 cells; however, the latter have a significant increase during relapses, which has not been observed with Th1. ${ }^{52}$

IL-17 acts on endothelial, epithelial and myeloid cells and fibroblasts. It potentiates IL-8, CXCL1, CXCL6, IL$1 \alpha$, IL-6, TNF- $\beta$, MIP-2 (macrophage inflammatory protein 2), MCP-1 (monocyte chemoattractant protein 1) and GMCS secretion, with the latter being a potent inducer of neutrophil migration ${ }^{53}$ (Fig. 2).

IL-23 stimulates IL-17 expression in TCD4 memory cells, which are able to co-express IFN- $\gamma$ (Th1). Both Th1 and Th17 cells cross the BBB; however, IFN- $-\gamma^{+} \mathrm{IL}-17^{+}$ TCD4 cells in patients with MS appear to cross it more efficiently, i.e., they are more encephalitogenic. ${ }^{54}$

The above data suggest that it would make sense to neutralize the p40 subunit, shared by IL-12 (Th1-inducer) and IL-23, which would block both profiles. However, in two clinical trials (briakinumab/ustekinumab), the effects 


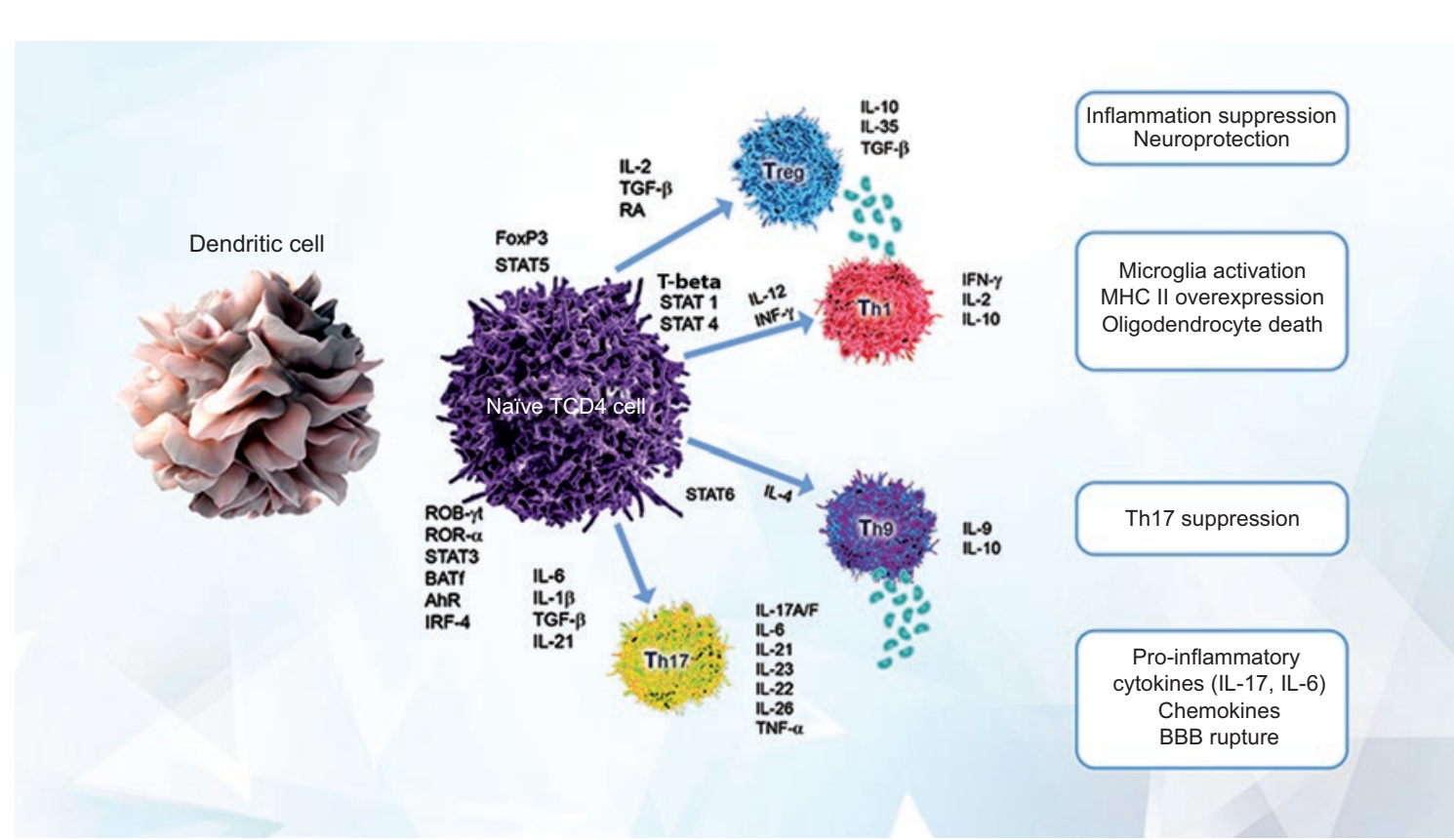

Figure 2. TCD4 cells effector profiles in MS. Differentiation of CD4+ Tlymphocytes precursors that are naïve to several CD4+ T cell lineages is controlled by specific transcription factors and stimulatory and inhibitory cytokines, the imbalance of which can lead to autoimmunity. Dendritic cells represent a fundamental point in the development of immune tolerance. They promote effector and suppressor responses, as it occurs with the Th9 profile and $T_{\text {reg. }}$. Tolerogenic dendritic cells could be a therapeutic alternative in the treatment of autoimmune diseases, such as MS. $T_{\text {reg }}=$ regulatory $T$ cell, IL = interleukin, TGF- $\beta=$ transforming growth factor-beta, FoxP3 = fork head box protein P3, STAT = signal transducer and activator of transcription, $R A=$ retinoic acid, $T N F=$ tumor necrosis factor, $A h R=$ aryl hydrocarbon receptor, IRF = interferon regulatory factor, IFN = interferon, $L T=$ lymphotoxin, $M H C=$ major histocompatibility complex, $B B B=$ blood-brain barrier .

of this blockade were shown not to be sufficient to justify them as first-line monotherapy. ${ }^{55,56}$

These results ma y be due in part to the fact that IL12 blockade can inhibit the IFN- $\gamma$-mediated protective function at early stages of the disease. IFN- $\beta$ can inhibit Th17 as part of its effects on clinical improvement, reinforcing the importance of the profile. ${ }^{57,58}$

For reasons unknown, some patients have a dominant profile, Th1 or Th17, which not only will impact on treatment but on the site of lesions: a Th17/Th1 ratio, with predominance of the former will be characterized by TCD4 and macrophage infiltration throughout the brain, while the predominance of the Th1 profile produces localized lesions. ${ }^{59}$

The role of Th1 and Th17 is not yet fully understood, there are probably not yet defined cytokines and transcription factors that act synergistically in the pathophysiology; for now, the role they play in neuroinflammation remains essential.

\section{$T_{\text {reg }}$ cells}

Keeping autoreactive cells under control to prevent autoimmunity is a task of the so-called "regulatory" cells, out of which the best characterized, although not the only one, is the $T_{\text {reg }}$ cell, which is mainly induced by TGF- $\beta$.
$\mathrm{T}_{\text {reg }}$ cells express the CD4+CD25+FoxP3+ markers and represent $5 \%$ of TCD4+ cells total population; their function is to control $\mathrm{T}$ cell expression, by internalizing the IL-2 receptor.

$\mathrm{T}_{\text {reg }}$ cells are dysfunctional in patients with MS due to a restricted TCR repertoire conferred to them by the fact of being inherently prone to autoimmunity due to a lack of diversity in their population. ${ }^{60,61}$

Additionally, TGF- $\beta$ signaling is lower in TCD4+ lymphocytes of patients with MS, which causes for these cells to be less sensitive to TGF- $\beta$; in part, this would explain why therapies directed to this target have failed. ${ }^{62}$

It is important underscoring that TGF $\beta$ and the aryl hydrocarbon receiver (AhR) signaling pathway can induce $T_{\text {reg }}$ or Th17, depending on the microenvironment and inflammatory factors such as TLR2, IL-6 and IFN- $\gamma$ ligands; this is highly important when considering a $\mathrm{T}_{\text {reg }}$-inducing therapy, since there is the possibility of Th17 induction.

Finally, glucocorticoids can transiently increase FOXP3 expression, thus favoring immunoregulation. ${ }^{63}$

\section{TCD8+ cells}

MS immunological basis and its experimental model, EEA, have largely focused on TCD $4{ }^{+}$cells as mediators 
and regulators of the disease. Induction of the disease by means of adoptive transfer of myelin-specific TCD4+ cells, favored the ignorance of a possible contribution of TCD $8^{+}$cells to pathophysiology. These represent the $\mathrm{T}$ cell predominant population in MS lesions.

TCD8 ${ }^{+}$cells express CD161 and chemokine receptor 6 (CCR6), by means of which they penetrate the SNC by binding to $\alpha 4$-integrin. They produce pro-inflammatory mediators such as IL-17 and their presence in the brain and CSF has been correlated with acute axonal damage. The best known effector functions include mechanisms of direct cytotoxicity to oligodendrocytes, neuronal death, demyelination and inflammatory cytokine production.

Their protecting functions depend on IFN- $\gamma$ and perforin production through direct cytotoxicity on TCD4+ autoreactive cells, pro-inflammatory cytokines modulation, CPA inhibition and IL-10 production. ${ }^{64}$

In patients with MS, their levels and function in peripheral blood are decreased and have been associated with suppressing activity on myelin-specific $\mathrm{TCD}^{+}$cells..$^{65,66}$ Their functions can be therapeutically induced with glatiramer acetate. Unlike CNS-specific $\mathrm{TCD}^{+}$cells, those that are pharmacologically induced are restricted to the HLA-E molecule. In peripheral blood, this is demonstrated with the inversion of the CD4/CD8 quotient, as a result of the TCD $8^{+}$increase at 12 hours of drug administration. ${ }^{67}$

Treatment with methylprednisolone leads to a significant increase of $\mathrm{TCD}^{+}{ }_{\text {reg }}$ in peripheral blood of patients with MS, which suggests that relapse recovery under treatment with glucocorticoids could be mediated, in part, by the regulating function of these cells. ${ }^{68}$ Although their role remains controversial, there is currently extensive evidence of its regulatory function, supported by findings of loss of said function during MS relapses and its restoration during improvement; the role it plays in MS final modulation will be of great interest in the future.

\section{Humoral immunity}

\section{B cells}

For decades, B cells role in MS was restricted to the production of antibodies and at this moment there is no doubt that they are important in the pathophysiology of the disease, since they are elevated in CNS lesions and CSF and simultaneously show clonal expansion and hypermutation, as a reflection of their activation. They are responsible for the production of oligoclonal bands, and their blockage by anti-CD20 antibodies such as rituximab and ocrelizumab has shown beneficial effects. ${ }^{69}$
The autoantigens suggested as targets of these antibodies remain unknown; therefore, the mechanisms that control B cell activation, selection and maturation remain a speculation.

The next question is, how do they migrate to the SNC? The mechanism is influenced by the large number of receptors they express, including CXCL13, a chemokine correlated with the conversion of the clinically isolated syndrome into MS and that facilitates their recruitment to the CNS. ${ }^{70}$

In comparison with $T$ cells, B cell infiltration in the CNS varies in the course of the disease. The meninges of patients with secondary progressive disease often contain tertiary lymphoid structures with plasma cells, $B$ cells, $T$ cells and follicular dendritic cells, resulting from chronic inflammation. ${ }^{71}$

Their effector function facilitates demyelination through antibody-dependent cell cytotoxicity, where cells of the innate immune system such as NKs recognize and bind to the antigen-antibody complex through the Fc-gamma receptor, triggering cytotoxicity and lysis; other described mechanisms are opsonization, phagocytosis and complement activation. ${ }^{72}$

CD20 monoclonal antibodies such as rituximab or ocrelizumab have been shown to be efficacious for reducing relapse rates. These drugs exhaust $B$ cell subsets but not plasma cells, so that their contributions lie in their ability to modulate antigen presentation and IL-6 production.73,74

$B$ cells produce cytokines such as IL-6, which activate microglia and are responsible for dendritic density loss in cortical plates. They also show a regulatory profile through the production of IL-10 and can act as APCs.

The role of $B$ cells in MS pathology is not limited to the production of antibodies, and their function on disease induction, relapse or progression remains to be elucidated.

\section{Conclusions}

Despite the great advances in the pathophysiology of MS, many questions remain to be answered. Possibly, future findings in epigenetics and innate immunity will allow to regulate the immune response prior to the release of autoreactive $T$ cells and antibody formation. Therapeutic targets should consider the complex interaction of the immune system, be highly specific and preserve or favor immunoregulation.

\section{References}

1. Van-Den-Elsen PJ, Van-Eggermond MC, Puentes F, Van-Der-Valk $P$, Baker D, Amor S. The epigenetics of multiple sclerosis and other related disorders. Mult Scler Relat Disord. 2014;3(2):163-175. 
2. Huang Q, Xiao B, Ma X, Qu M, Li Y, Nagarkatti $P$, et al. MicroRNAs associated with the pathogenesis of multiple sclerosis. J Neuroimmunol. 2016;295-296:148-161.

3. Ebers G. Interactions of environment and genes in multiple sclerosis. Lancet Neurol. 2008;7:268-277.

4. Küçükali Ci, Kürtüncü M, Çoban A, Çebi M, Tüzün E. Epigenetics of multiple sclerosis: an updated review. Neuromolecular Med. 2015;17:83-96.

5. Koch MW, Metz LM, Kovalchuk O. Epigenetics and miRNAs in the diagnosis and treatment of multiple sclerosis. Trends Mol Med. 2013;19:23-30.

6. Pistono C, Osera C, Boiocchi C, Mallucci G, Cuccia M, Bergamaschi R et al. What's new about oral treatments in multiple sclerosis? Immunogenetics still under question. Pharmacol Res. 2017;120:279-293.

7. Peedicayil J. Epigenetic drugs for multiple sclerosis. Curr Neuropharmacol. 2016;14:3-9.

8. Langrish $\mathrm{CL}$, Chen Y, Blumenschein WM, Mattson J, Basham B, Sedgwick JD, et al. IL-23 drives a pathogenic $T$ cell population that induces autoimmune inflammation. J Exp Med. 2005;201:233-240

9. Cua DJ, Sherlock J, Chen Y, Murphy C a, Joyce B, Seymour B, et al. Interleukin-23 rather than interleukin-12 is the critical cytokine for autoimmune inflammation of the brain. Nature. 2003;421:744-748

10. Simmons SB, Liggitt D, Goverman JM. Cytokine-regulated neutrophil recruitment is required for brain but not spinal cord inflammation during experimental autoimmune encephalomyelitis. J Immunol. 2014;193: 555-563.

11. Haak S, Croxford AL, Kreymborg K, Heppner FL, Pouly S, Becher B, et al. IL-17A and IL-17F do not contribute vitally to autoimmune neuro-inflammation in mice. J Clin Invest. 2009;119:61-69.

12. Komiyama $Y$, Nakae $S$, Matsuki $T$, Nambu A, Ishigame $H$, Kakuta $S$, et al. IL-17 plays an important role in the development of experimental autoimmune encephalomyelitis. J Immunol. 2006;177:566-573.

13. Sonderegger I, lezzi G, Maier R, Schmitz N, Kurrer M, Kopf M. GM-CSF mediates autoimmunity by enhancing IL-6-dependent Th17 cell development and survival. J Exp Med. 2008;205:2281-2294

14. Lees JR, Golumbek PT, Sim J, Dorsey D, Russell JH. Regional CNS responses to IFN-gamma determine lesion localization patterns during EAE pathogenesis. J Exp Med. 2008;205:2633-2642.

15. Simmons RD, Willenborg DO. Direct injection of cytokines into the spinal cord causes autoimmune encephalomyelitis-like inflammation. J Neuro Sci. 1990;100:37-42.

16. Billiau A, Heremans $H$, Vandekerckhove $F$, Dijkmans $R$, Sobis $H$, Meulepas $E$, et al. Enhancement of experimental allergic encephalomyelitis in mice by antibodies against IFN-gamma. J Immunol. 1988;140:1506-1510.

17. TNF neutralization in MS: results of a randomized, placebo-controlled multicenter study. The Lenercept Multiple Sclerosis Study Group and The University of British Columbia MS/MRI Analysis Group. Neurology. 1999;53:457-465.

18. Croxford AL, Spath S, Becher B. GM-CSF in neuroinflammation: licensing myeloid cells for tissue damage. Trends Immunol. 2015;36:651-662.

19. Lee PW, Severin ME, Lovett-Racke AE. TGF- $\beta$ regulation of encephalitogenic and regulatory $\mathrm{T}$ cells in multiple sclerosis. Eur $\mathrm{J}$ Immunol. 2017;47:446-453.

20. Lee PW, Yang Y, Racke MK, Lovett-Racke AE. Analysis of TGF- $\beta 1$ and TGF- $\beta 3$ as regulators of encephalitogenic Th17 cells: implications for multiple sclerosis. Brain Behav Immun. 2015;46:44-49.

21. Huss DJ, Winger RC, Peng H, Yang Y, Racke MK, Lovett-Racke AE. TGF-beta enhances effector Th1 cell activation but promotes self-regulation via IL-10. J Immunol. 2010;184:5628-5636.

22. Letterio JJ, Geiser AG, Kulkarni AB, Dang H, Kong L, Nakabayashi T, et al. Autoimmunity associated with TGF-b1-deficiency in mice is dependent on MHC class II antigen expression. J Clin Invest. 1996;98: 2109-2119.

23. Gorelik L, Flavell RA. Abrogation of TGFb signaling in T cells leads to spontaneous $\mathrm{T}$ cell differentiation and autoimmune disease. Immunity. 2000;12:171.

24. Schmitt E, Bopp T. Discovery and initial characterization of Th9 cells: the early years. Semin Immunopathol. 2016;39:1-6.

25. Ruocco G, Rossi S, Motta C, Macchiarulo G, Barbieri F, De Bardi M, et al. T helper 9 cells induced by plasmacytoid dendritic cells regulate interleukin-17 in multiple sclerosis. Clin Sci (Lond). 2015;129(4):291-303.

26. Ding X, Cao F, Cui L, Ciric B, Zhang GX, Rostami A. IL-9 signaling affects central nervous system resident cells during inflammatory stimuli. Exp Mol Pathol. 2015;99:570-574.

27. Bsibsi M, Ravid R, Gveric D, Van-Noort JM. Broad expression of Toll-like receptors in the human central nervous system. J Neuropathol Exp Neurol. 2002;61:1013-1021.

28. Miranda-Hernández S, Baxter AG. Role of toll-like receptors in multiple sclerosis. Am J Clin Exp Immunol. 2013;2:75-93.

29. Farez MF, Quintana FJ, Gandhi R, Izquierdo G, Lucas M, Weiner HL. Toll-like receptor 2 and poly(ADP-ribose) polymerase 1 promote central nervous system neuroinflammation in progressive EAE. Nat Immunol. 2009;10:958-964.

30. Correale J, Fiol M, Gilmore W. The risk of relapses in multiple sclerosis during systemic infections. Neurology. 2006;67:652-659.
31. Hossain MJ, Tanasescu R, Gran B. Innate immune regulation of autoimmunity in multiple sclerosis: focus on the role of Toll-like receptor 2. J Neuroimmunol. 2016;304:11-20.

32. Liang $P$, Le W. Role of autophagy in the pathogenesis of multiple sclerosis. Neurosci Bull. 2015;31:435-444.

33. Inoue M, Williams KL, Gunn MD, Shinohara ML. NLRP3 inflammasome induces chemotactic immune cell migration to the CNS in experimental autoimmune encephalomyelitis. Proc Natl Acad Sci U S A. 2012;109:1048010485.

34. Ming X, Li W, Maeda Y, Blumberg B, Raval S, Cook SD, et al. Caspase-1 expression in multiple sclerosis plaques and cultured glial cells. J Neurol Sci. 2002;197:9-18.

35. Seppi D, Puthenparampil M, Federle L, Ruggero S, Toffanin E, Rinaldi F, et al. Cerebrospinal fluid IL-1 $\beta$ correlates with cortical pathology load in multiple sclerosis at clinical onset. J Neuroimmunol. 2014;270:56-60.

36. Inoue $\mathrm{M}$, Shinohara ML. The role of interferon- $\beta$ in the treatment of multiple sclerosis and experimental autoimmune encephalomyelitis - in the perspective of inflammasomes. Immunology. 2013;139:11-18.

37. Noroozi S, Meimand HAE, Arababadi MK, Nakhaee N, Asadikaram G. The effects of IFN- $\beta$ 1a on the expression of inflammasomes and apoptosis-associated speck-like proteins in multiple sclerosis patients. Mol Neurobiol. 2017:54:3031-3037.

38. Inoue $M$, Chen $P$, Siecinski S, Li Q, Liu C, Steinman L, et al. An interferon-b-resistant and NLRP3 inflammasome-independent subtype of EAE with neuronal damage. Nat Neurosci. 2016;19:1-13.

39. Malhotra S, Río J, Urcelay E, Nurtdinov R, Bustamante MF, Fernández O, et al. NLRP3 inflammasome is associated with the response to IFN- $\beta$ in patients with multiple sclerosis. Brain. 2015;138:644-652.

40. Gross CC, Schulte-Mecklenbeck A, Wiendl H, Marcenaro E, Kerlero-De-Rosbo N, Uccelli A, et al. Regulatory functions of natural killer cells in multiple sclerosis. Front Immunol. 2016;7:606.

41. Ascherio A, Munger KL. Environmental risk factors for multiple sclerosis. Part II: noninfectious factors. Ann Neurol. 2007:61:504-513.

42. Martínez-Rodríguez JE, Cobo-Calvo A, Villar LM, Munteis E, Blanco Y, Rasal R, et al. Adaptive natural killer cell response to cytomegalovirus and disability progression in multiple sclerosis. Mult Scler. 2015;22:741-752.

43. Hu Y, Turner MJ, Shields J, Gale MS, Hutto E, Roberts BL, et al. Investigation of the mechanism of action of alemtuzumab in a human CD52 transgenic mouse model. Immunology. 2009;128:260-270.

44. Skarica M, Eckstein C, Whartenby KA, Calabresi PA. Novel mechanisms of immune modulation of natalizumab in multiple sclerosis patients. J Neuroimmunol. 2011;235:70-76.

45. Bielekova B, Howard T, Packer AN, Richert N, Ohayon J, Waldmann TA et al. NIH Public Access. Inflammation. 2010;66:483-489.

46. Gross CC, Schulte-Mecklenbeck A, Rünzi A, Kuhlmann T, Posevitz-Fejár A, Schwab N, et al. Impaired NK-mediated regulation of T-cell activity in multiple sclerosis is reconstituted by IL-2 receptor modulation. Proc Natl Acad Sci. 2016;113:E2973-E2982.

47. Jiang W, Chai NR, Maric D, Bielekova B. Unexpected role for granzyme $\mathrm{K}$ in CD56bright NK cell-mediated immunoregulation of multiple sclerosis. J Immunol. 2011;187:781-790.

48. Voskuhl RR, Martin R, Bergman C, Dalal M, Ruddle NH, McFarland HF. T helper 1 (Th1) functional phenotype of human myelin basic protein-specific T lymphocytes. Autoimmunity. 1993;15:137-143.

49. Matusevicius D, Kivisäkk P, He B, Kostulas N, Ozenci V, Fredrikson S, et al. Interleukin-17 mRNA expression in blood and CSF mononuclear cells is augmented in multiple sclerosis. Mult Scler. 1999;5:101-104.

50. Ishizu T, Osoegawa M, Mei FJ, Kikuchi H, Tanaka M, Takakura Y, et al. Intrathecal activation of the IL-17/IL-8 axis in opticospinal multiple sclerosis. Brain. 2005:128:988-1002.

51. Lock C, Hermans G, Pedotti R, Brendolan A, Schadt E, Garren H, et al. Gene-microarray analysis of multiple sclerosis lesions yields new targets validated in autoimmune encephalomyelitis. Nat Med. 2002;8:500-508.

52. Brucklacher-Waldert V, Stuerner K, Kolster M, Wolthausen J, Tolosa E. Phenotypical and functional characterization of T helper 17 cells in multiple sclerosis. Brain. 2009;132:3329-3341.

53. Jovanovic D V, Di-Battista JA, Martel-Pelletier J, Jolicoeur FC, He Y, Zhang M, et al. IL-17 stimulates the production and expression of proinflammatory cytokines, IL-beta and TNF-alpha, by human macrophages. $\mathrm{J}$ Immunol. 1998;160:3513-3521.

54. Kebir H, Ifergan I, Alvarez Jl, Bernard M, Poirier J, Arbour N, et al. Preferential recruitment of interferon-gamma-expressing TH17 cells in multiple sclerosis. Ann Neurol. 2009;66:390-402.

55. Vollmer TL, Wynn DR, Alam MS, Valdes J. A phase 2, 24-week, randomized, placebo-controlled, double-blind study examining the efficacy and safety of an anti-interleukin-12 and -23 monoclonal antibody in patients with relapsing-remitting or secondary progressive multiple sclerosis. Mult Scler. 2011;17:181-191.

56. Segal BM, Constantinescu CS, Raychaudhuri A, Kim L, Fidelus-Gort R, Kasper LH. Repeated subcutaneous injections of IL12/23 p40 neutralising antibody, ustekinumab, in patients with relapsing-remitting multiple sclerosis: a phase II, double-blind, placebo-controlled, randomised, dose-ranging study. Lancet Neurol. 2008;7:796-804. 
57. Ramgolam VS, Sha Y, Jin J, Zhang X, Markovic-Plese S. IFN-beta inhibits human Th17 cell differentiation. J Immunol. 2009;183:5418-5427.

58. Durelli L, Conti L, Clerico M, Boselli D, Contessa G, Ripellino P, et al T-helper 17 cells expand in multiple sclerosis and are inhibited by interferon-beta. Ann Neurol. 2009;65:499-509.

59. Grigoriadis N, Van-Pesch V. A basic overview of multiple sclerosis immunopathology. Eur J Neurol. 2015;22:3-13.

60. Viglietta V, Baecher-Allan C, Weiner HL, Hafler DA. Loss of functiona suppression by $\mathrm{CD} 4+\mathrm{CD} 25+$ regulatory $\mathrm{T}$ cells in patients with multiple sclerosis. J Exp Med. 2004;199:971-979.

61. Haas J, Fritzsching B, Trübswetter $\mathrm{P}$, Korporal M, Milkova L, Fritz B et al. Prevalence of newly generated naive regulatory $T$ cells (Treg) is critical for Treg suppressive function and determines Treg dysfunction in multiple sclerosis. J Immunol. 2007;179:1322-1330.

62. Calabresi PA, Fields NS, Maloni HW, Hanham A, Carlino J Moore J, et al. Phase 1 trial of transforming growth factor beta 2 in chronic progressive MS. Neurology. 1998;51:289-292.

63. Braitch M, Harikrishnan S, Robins RA, Nichols C, Fahey AJ, Showe L, et al. Glucocorticoids increase CD4+CD25high cell percentage and Foxp3 expression in patients with multiple sclerosis. Acta Neurol Scand. 2009;119:239-245.

64. Sinha S, Boyden AW, Itani FR, Crawford MP, Karandikar NJ. CD8+ T-cells as immune regulators of multiple sclerosis. Front Immunol. 2015;6:619.

65. Balashov KE, Khoury SJ, Hafler DA, Weiner HL. Inhibition of T cell responses by activated human CD8+ T cells is mediated by interferon-gam$\mathrm{ma}$ and is defective in chronic progressive multiple sclerosis. J Clin Invest. 1995;95:2711-2719.

66. Baughman EJ, Mendoza JP, Ortega SB, Ayers CL, Greenberg BM, Frohman EM, et al. Neuroantigen-specific CD8+ regulatory T-cell func- tion is deficient during acute exacerbation of multiple sclerosis. J Autoimmun. 2011;36:115-124.

67. Ayers CL, Mendoza JP, Sinha S, Cunnusamy K, Greenberg BM, Frohman EM, et al. Modulation of immune function occurs within hours of therapy initiation for multiple sclerosis. Clin Immunol. 2013;147:105-119.

68. Aristimuño C, Navarro J, De-Andrés C, Martínez-Ginés ML, GiménezRoldán S, Fernández-Cruz E, et al. Expansion of regulatory CD8+ T-lymphocytes and fall of activated CD8+ T-lymphocytes after iv methyl-prednisolone for multiple sclerosis relapse. J Neuroimmunol. 2008:204:131-135.

69. Cepok S, Jacobsen M, Schock S, Omer B, Jaekel S, Böddeker I, et al. Patterns of cerebrospinal fluid pathology correlate with disease progression in multiple sclerosis. Brain. 2001;124:2169-2176.

70. Krumbholz M, Theil D, Cepok S, Hemmer B, Kivisäkk P, Ransohoff RM, et al. Chemokines in multiple sclerosis: CXCL12 and CXCL13 up-regulation is differentially linked to CNS immune cell recruitment. Brain. 2006;129:200-211.

71. Howell OW, Reeves CA, Nicholas R, Carassiti D, Radotra B, Gentleman SM, et al. Meningeal inflammation is widespread and linked to cortical pathology in multiple sclerosis. Brain. 2011;134:2755-2771.

72. Roche PA, Furuta K. The ins and outs of MHC class II-mediated antigen processing and presentation. Nat Rev Immunol. 2015;15:203-216.

73. Hauser S, Waubant E, Arnold DL, Vollmer T, Antel J, Fox RJ, et al. B-cell depletion with rituximab in relapsing-remitting multiple sclerosis. $N$ Engl J Med. 2008;358:676-688

74. Kappos L, Li D, Calabresi PA, O'Connor P, Bar-Or A, Barkhof F, et al. Ocrelizumab in relapsing-remitting multiple sclerosis: a phase 2, randomised, placebo-controlled, multicentre trial. Lancet. 2011;378:1779-1787. 